\title{
Hyperthyroidism presenting as pyramidal tract disease
}

\author{
Pamela J Shaw, David Bates, Pat Kendall-Taylor
}

Thyroid function should be evaluated in all patients with pyramidal tract disease of uncertain origin
Departments of Neurology and Medicine, University of Newcastle upon Tyne and Royal Victoria

Infirmary, Newcastle upon Tyne

Pamela J Shaw, MD, first assistant in neurology David Bates, FRCP, consultant and senior lecturer in neurology

Pat Kendall-Taylor, FRCP, consultant physician and professor of endocrinology

Correspondence to: $\mathrm{Dr}$ Pamela J Shaw, Department of Neurology, Ward 6, Royal Victoria Infirmary, Newcastle upon Tyne NE1 4LP.
Recognised neuromuscular disorders associated with hyperthyroidism include thyrotoxic myopathy, muscle cramps, periodic paralysis, myasthenia gravis, exophthalmic ophthalmoplegia, and thyrotoxic neuropathy. ${ }^{1-7}$ Thyroid hyperactivity may also affect the central nervous system, resulting in confusional states, behavioural abnormalities, coma, seizures, or movement disorders. ${ }^{8 \cdot 11}$ Pyramidal tract dysfunction is not usually listed among the well established neurological syndromes associated with hyperthyroidism. Though rare, it is important not to miss this condition, which is reversible with antithyroid treatment and which may be mistaken for a progressive and untreatable illness such as motor neurone disease.

\section{Case report}

A 60 year old printer presented with a three month history of progressive worsening of gait associated with weakness and stiffness of the legs. By the time of admission he was unable to walk more than 30 metres without resting, had great difficulty climbing and descending stairs, and could no longer manage his job. $\mathrm{He}$ did not complain of weakness of arms or of disturbed sensory or sphincter function. He had felt less well than normal for 18 months with general malaise, reduced energy, intermittent aching in limbs, and weight loss of $6.4 \mathrm{~kg}$. There was no history of previous neurological problems, and his history contained nothing of note, except for mild hypertension, which had been treated with atenolol and chlorthalidone for two years.

On physical examination he looked thin and unwell. There was a small central goitre and a fine tremor of the outstretched hands. Hands and feet were cool and dry, the resting pulse was $66-80$ beats $/ \mathrm{min}$, and there were no appreciable eye signs. Neurological examination showed a slow, stiff gait with unsteadiness on tandem walking. Cognitive function and speech were normal. Cranial nerve examination detected only mild bilateral weakness of orbicularis oculi. Arm muscles were generally thin, without focal wasting or fasciculation. There was mild global weakness, more pronounced in the extensors than the flexors. Musculature of the legs was generally thin and tone was noticeably increased with sustained clonus at the ankles and patellar clonus. There was moderately severe weakness (MRC grade 4/5) in hip flexion, knee flexion, and ankle dorsiflexion, the right side being slightly worse than the left. Extensor muscles, including quadriceps and gluteus maximus, were of normal power. Jaw jerk was brisk and the tendon reflexes in all limbs were pathologically brisk, with absent abdominal reflexes and extensor plantar responses. There was no sensory disturbance and spinal examination showed nothing abnormal.

Investigation disclosed a serum thyroxine concentration of $295 \mathrm{nmol} / \mathrm{l}$ (normal $63-131 \mathrm{nmol} / \mathrm{l}$ ) and a free thyroxine index of 126 (21-36). Sensitive thyroid stimulating hormone assay yielded a concentration of $0 \cdot 15 \mathrm{mU} / 1(0 \cdot 25-4 \cdot 3 \mathrm{mU} / \mathrm{l})$. Thyroid microsomal antibodies were detected at a titre of $1 / 400$; other autoantibodies were not detected. Thyrotrophin binding inhibiting immunoglobulin index was 31.6 (normal $<18 \cdot 0$ ). Pertechnetate thyroid scan showed uniform uptake in a bulky thyroid, the 20 minute uptake being $9 \cdot 7 \%$ (normal $<3 \cdot 0 \%$ ). Normal values were obtained for full blood count; blood glucose, urea, creatinine, and electrolyte concentrations; and liver function tests and a chest radiograph and electrocardiogram were normal. Serum calcium concentration was mildly raised at $2.6 \mathrm{mmol} / \mathrm{l}$ (normal $2 \cdot 2-2 \cdot 5 \mathrm{mmol} / \mathrm{l}$ ). Venereal Disease Research Laboratory test gave a negative result. Creatine kinase activity was normal and no appreciable abnormalities were found on nerve conduction studies or electromyography. Several other neurological investigative procedures were undertaken to exclude other possible causes of pyramidal tract dysfunction. Magnetic resonance imaging of the brain and spinal cord showed nothing abnormal. Studies of evoked potentials elicited a slightly delayed response of dubious relevance from the left eye but no other abnormalities. The cerebrospinal fluid was normal with a white cell count of less than $1 \times 10^{6} / 1$, a total protein concentration of $0.3 \mathrm{~g} / \mathrm{l}(10 \% \mathrm{IgG})$, and a glucose concentration of $3.4 \mathrm{mmol} / \mathrm{l}$.

The patient began treatment with carbimazole and his response was dramatic. Within four weeks he could walk almost normally and his neurological signs were greatly improved. By three months the clonus, hyperreflexia, and extensor plantar responses were no longer present and muscle power was normal apart from mild weakness of hip flexion on the right. At that stage we decided to stop the carbimazole so that we could give radioactive iodine four weeks later. Within two weeks he reported a recurrence of weakness of the legs and difficulty with walking. Examination showed that the lower limb pyramidal tract signs had reappeared, though were less severe than before. His serum thyroxine concentration was $286 \mathrm{nmol} / \mathrm{l}$. Serum triiodothyroxine concentration was $5 \cdot 3 \mathrm{nmol} / \mathrm{l}$ (normal reference range $1 \cdot 2-3 \cdot 0 \mathrm{nmol} / \mathrm{l}$ ). A few days after the treatment with iodine- 131 carbimazole was reinstituted. Within six weeks the neurological abnormalities had again disappeared apart from mild weakness of hip flexion.

\section{Discussion}

A causal relation between the pyramidal tract signs and thyroid overactivity in our patient was likely for several reasons. Firstly, extensive investigation showed no evidence of any other intracranial or spinal cause for the neurological dysfunction. Secondly, there was striking resolution of the neurological signs with antithyroid treatment and recurrence with relapse of the hyperthyroidism when the treatment was withdrawn.

Paraparesis associated with thyrotoxicosis was described by Charcot in 1889.'2 This was a flaccid paraparesis with absent reflexes and without associated upper motor neurone signs. The condition was labelled Basedow's paraplegia by Joffroy in $1894 .^{13}$ Similar patients described later were shown to have a thyrotoxic polyneuropathy affecting predominantly the legs. ${ }^{1+}$ Upper motor neurone signs in association with 
thyrotoxicosis have only rarely been reported. Early publications contain reports of patients with thyrotoxicosis who developed hemiparesis or paraparesis. In many of these the cause-effect relation is obscure and definite conclusions cannot be reached. In a review of published work we found only nine adequately documented cases of pyramidal tract dysfunction in association with hyperthyroidism. ${ }^{916-22}$ Features emphasised in those reports included spastic weakness in the legs as well as hyperreflexia, clonus, and extensor plantar responses. Occasional patients also have impaired vibration sense and proprioceptive function, ${ }^{17} 19$ bladder spasticity and urinary incontinence, ${ }^{1820}$ or impaired consciousness. ${ }^{9}$ Some patients have lower motor neurone as well as upper motor neurone signs, a combination producing a clinical picture similar to motor neurone disease. ${ }^{22}$ Treatment of the hyperthyroid state usually results in complete or nearly complete recovery of the upper motor neurone signs. ${ }^{9} 16182021$

The pathophysiological basis of pyramidal tract dysfunction in hyperthyroidism is unknown. No histopathological studies have been reported. It is becoming clear, however, that thyroid hormones act directly on the adult nervous system in complex and important ways. In mature rat brain hyperthyroidism causes a substantial increase in striatal $\beta$ adrenoceptors, striatal dopaminergic neuronal activity, and presynaptic $\alpha_{2}$ adrenoceptor function. ${ }^{23}$ Complex and regionally specific changes in brain nuclei concentrations of serotonin, 5-hydroxyindoleacetic acid, and substance $P$ have also been recorded. ${ }^{24}$ Activities of some brain enzymes are sensitive to thyroid dysfunction. Hyperthyroidism reduces the activity of glutamate dehydrogenase $^{25}$ and pyruvate dehydrogenase ${ }^{26}$ in the brain. The pathophysiological effect of fluctuations of thyrotrophin releasing hormone in the hyperthyroid state may be important in the genesis of neurological complications. ${ }^{27}$ Further histopathological and neurochemical studies in animal models may help shed light on the mechanisms of pyramidal tract dysfunction in hyperthyroidism.

In conclusion, pyramidal tract dysfunction appears to be a genuine though rarely documented complication of thyrotoxicosis. We describe this case to emphasise that thyroid function should be evaluated in all patients with unexplained pyramidal tract dysfunction and in those in whom a diagnosis of motor neurone disease is being considered. This applies particularly to groups such as the elderly and patients taking $\beta$ blockers, in whom clinical signs of hyperthyroidism may be masked.

1 Green R. The thyroid gland: its relationship to neurology. In: Vinken PJ, Bruyn GW, eds. Handbook of clinical neurology. Vol 27. Amsterdam: North Holland Publishing, 1976:255-78.

2 Engel AG. Neuromuscular manifestations of Graves' disease. Mayo Clin Proc 1972;47:919-25.

3 Adams RD, DeLong GR. Organ system manifestations of thyrotoxicosis. The neuromuscular system and brain. In: Ingbar SH, Braveman LE, eds. Weuromuscular system and brain. In: Ingbar SH, Braveman

4 Araki S, Terao A, Matsumoto I, Narazaki T, Kuriowa Y. Muscle cramps in chronic thyrotoxic myopathy: report of a case. Arch Neurol 1968;19:315-20. Logothetis J. Neurologic and muscular manifestations of hyperthyroidism. arch Neurol 1961:5:87-97.

6 Kudriavlev T. Neurologic complications of thyroid dysfunction. Adv Neurol 1978;19:619-36.

7 Swanson JW, Kelly JJ, McConahey WM. Neurologic aspects of thyroid dysfunction. Mayo Clin Proc 1981;56:504-12.

8 Rockey PH, Grief RJ. Behavioral dysfunction in hyperthyroidism. Improvement with treatment. Arch Intern Med 1980;140:1194-7.

9 Newcomer J, Haire W, Hartman CR. Coma and thyrotoxicosis. Ann Neurol 1983;14:689-90.

10 Jabbari B, Huott AD. Seizures in thyrotoxicosis. Epilepsia 1980;21:91-6.

11 Fischbeck KH, Layzer RB. Paroxysmal choreoathetosis associated with thyrotoxicosis. Ann Neurol 1979;6:453-4.

12 Charcot J. Nouveaux signes de la maladie de Basedow. Bulletin Médical 1889;3:147-9.

13 Joffroy MA. Hospice de la Salpêtrière, clinique nerveuse, leçons faites en Décembre, 1891. Progrès Médical 1894;22:61-2.

14 Feibel JH, Campa JF. Thyrotoxic neuropathy (Basedow's paraplegia) I Neurol Neurosurg Psychiatry 1976;39:491-7.

15 Sattler H. Basedow's disease. 1908. Marchand GW, Marchand JF, transl. New York: Grune and Stratton, 1952

16 Ravera JJ, Cervino JM, Fernandez G, et al. Two cases of Graves' disease with signs of a pyramidal lesion. Improvement in neurologic signs during treatment with antithyroid drugs. Fournal of Clinical Endocrinology 1960;20: 876-80.

17 Melamed E, Berman M, Lavy S. Posterolateral myelopathy associated with thyrotoxicosis. N Engl f Med 1975;293:778-9.

18 Bulens C. Neurologic complications of hyperthyroidism. Remission of spastic paraplegia dementia and optic neuropathy. Arch Neurol 1981:38:669-70.

19 Florin T, Walls RS. Neurological complications of thyrotoxicosis in the élderly. Ann Neurol 1984;15:608.

20 Garcia CA, Fleming H. Reversible corticospinal tract disease due to hyperthyroidism. Arch Neurol 1977;34:647-8.

21 Platt G, Cranford RE, Anderson DC, Hubbard JE. Thyrotoxic periodic paralysis with upper motor neurone findings. FAMA 1978;240:2456-66.

22 Fisher M, Mateer JE, Ullrich I, Gutrecht JA. Pyramidal tract deficits and polyneuropathy in hyperthyroidism. Combination clinically mimicking amyotrophic lateral sclerosis. Am f Med 1985;78:1041-4

23 Atterwill CK, Bunn SJ, Atkinson DJ, et al. Effects of thyroid status on presynaptic alpha 2 adrenoceptor function and beta adrenoceptor binding in the rat brain. $\mathcal{F}$ Neural Transm 1984;59:43-55.

24 Savard P, Merand Y, Dipaolo T, et al. Effects of thyroid state on serotonin 5 hydroxyindoleacetic acid and substance $P$ contents in discrete brain nuclei of adult rats. Neuroscience 1983;10:1399-1404.

25 Fernandez-Pastor JM, Morell M, Menendez-Patterson A, et al. Effect of experimental changes in thyroid function on oxidative metabolism an Fisiol 1983;39:311-6.

26 Murthy AS, Baquer NZ. Changes of pyruvate dehydrogenase in rat brain with thyroid hormones. Enzyme 1982;28:48-53.

27 Glaser GH. Neurological aspects of thyroid disease. In: Matthews WB, Glaser $\mathrm{GH}$, eds. Recent advances in clinical neurologv 4. Edinburgh: Churchill Livingstone, 1984:141-57.

(Accepted 31 August 1988)
James Burton and his wife Peggy had a vocation It fortified them through wartime difficulties, through training and preparation, and it took them to the Congo, where they encountered difficulties and deprivation; their first strangulated hernia was tackled with a roll of instruments last used in the dissecting room. Illness intervened, demanding their return to the United Kingdom, and there they were perturbed to discover the "throw away" medicine of the North. Thus was laid the foundation of the Joint Mission Hospital Equipment Board, known over a grateful world as ECHO.

ECHO gleans. No item is too large or too small-sell it your outdated Land-rover or give it a single unopened suture pack. All is grist to its mill. Suture material, together with needles and other minor items, are stored in trays to be picked over by enthusiastic visitors or added to overseas parcels. Land-rovers are stripped down, completely rebuilt to individual specification, and dispatched at a price well below that of a new vehicle. Nearly 2000 hospitals in 120 Third World countries are supplied from the large complex in Coulsdon, every item scrutinised, repaired if necessary, and certified fit for immediate use.

For many of these health units ECHO is the major supporter. But there are also emergencies, and it is to ECHO that both governments and the larger organisations turn. In Biafra, Eritrea, and Bhopal, earthquake, flood, and famine, ECHO has played an invaluable part in lessening suffering. The rapid response it can mount, together with its reputation for reliability, efficiency, and innovation, has made it unique.

Innovation is a strong point. Receptive to ideas from any quarter ECHO has commissioned and designed a range of equipment that is tough, portable, and versatile, like the tropical refrigerator that will run on electricity, paraffin, or bottled gas. A veterinary division has been developed, the drug department greatly expanded, and a technical workshop started in Uganda.

ECHO needs money. As with every agency serving the Third World, postage and transport are costly items. But it also needs "things." Hospital workers-please make sure that nothing is wasted. Keep reminding supplies officers, senior nursing staff, and colleagues; let nothing usable be thrown away. General practitioners also-if you buy a new electronic stethoscope then send the old one to ECHO, and its second life may be more valuable than its first. Contact ECHO at Ullswater Crescent, Coulsdon, Surrey CR3 2HR (01 6602220 ).

ANNE SAVAGE, London 